\title{
Development and Application of an English Network Teaching System Based on MOOC
}

\author{
https://doi.org/10.3991/ijet.v13i07.8802 \\ Nina Zhang \\ Shandong Management University, Shandong Jinan, China \\ ninazhang 28103 @ $21 \mathrm{cn} . \mathrm{com}$
}

\begin{abstract}
Compared to traditional university network learning, MOOC teaching emphasized "student-centered", "knowledge modularity" and "interaction and communication". In order to construct a perfect college English network teaching environment, based on the in-depth analysis of the characteristics of the MOOC teaching model, a multimedia and multi-resources college English learning environment was established. In this environment, students could make individualized learning on their own pace. The system integrated learning platforms such as online learning, interactive communication, online operation, curriculum publishing and news bulletin, which were in line with MOOC teaching ideas. The results showed that, based on the idea of MOOC teaching, the system effectively promoted students' learning desire to transform knowledge into active learning behavior under the support of learning environment and advanced learning tools. To sum up, the system effectively improves the effect of college English teaching on the Internet.
\end{abstract}

Keywords-MOOC; English; network teaching; development and application

\section{Introduction}

With the continuous updating and development of network technology and information technology, online education is attracting more and more attention of teachers and educators. Online education can also be understood as distance education or online learning. Generally, it refers to a teaching model based on the network platform. In the information age of rapid development of science and technology, as a supplement to traditional education, online education occupies a growing proportion in people's lives. MOOC (English short for Massive Open Online Courses) has become one of the hotspots of teaching and learning in the world. The design of the MOOC teaching model is designed to achieve an online classroom for the public. Online learning is carried out through online classes, replacing some of the previous traditional face-to-face courses. MOOC is also the latest development of distance education. People do not have to study activities in the same time period and the same 
place in the same place. It is realized and developed through the form of open education resources. It has many characteristics, such as large scale and openness, and has become a hot spot of research at home and abroad.

Traditional educational institutions are also constantly utilizing the online resources, embracing the Internet. Also, the Internet is apparently imperceptibly affecting and updating the existing educational system, like the impact it had on retail, media and other fields. At present, the teaching mode of colleges and universities is basically to transmit knowledge in the way as if teachers are broadcasting. It is undeniable that this method plays an important role in the age of the only source of the students' learning knowledge. However, in the information age of diversified sources of knowledge and diversified learning methods, college students are having more selfrespect and are stronger, they yearn for autonomy, independence, creativity and selfvalue realization. The teaching mode is also being questioned by students, many are making their doubts heard.

\section{$2 \quad$ Literature review}

In the study, the scholar Baran pointed out that since 2012, the MOOC (Massive Open Online Courses) began a global revolution in digital education, allowing anyone eager to acquire knowledge to learn the well-known courses of the world's famous schools through the network and make the certification possible [1]. Some scholars, like Möller, emphasized that the development of new MOOC education mode in China has attracted more and more attention from governments and universities [2]. However, a researcher at Zhenhua shows that the attitude toward the development of MOOC is mixed [3]. On the one hand, it pays more attention to the severe challenge of the popularization of MOOC to the survival of colleges and universities; on the other hand, it is believed that MOOC has not yet formed a system in Chinese society and can only exist as a supporting role under the Chinese educational mechanism.

In the study, the scholar, Ying, pointed out that if more focus should be paid on exploring the educational model that is consistent with social development and the progress of human civilization, efforts will be made to how to integrate with traditional education so that it can play a greater role in education, instead of being replaced [4]. In addition, Rayyan also stressed that, along with the rapid development of modern information technology, various aspects of the country's educational philosophy, educational management, educational system and teaching organization and methods have been changed accordingly, and the "Internet plus" has risen as a national strategy. Followed by the rapid rise of online education, due attention and concerns were also aroused [5].

Trivedi points out that Coursera is the largest MOOC site in the world, with nearly five million registered users and more than 350 online courses in collaboration with more than 80 universities around the world. Data from September 2013 showed that the number of visitors from China has ranked ninth in the world. In September, courses offering multiple Chinese subtitles were launched, providing unlimited possibilities for the localization and expansion of Coursera. Kaplan research found that MOOC 
movement swept China. Before, they traveled to the world's famous universities to study. Now a new way of learning is rising in China, without the national gate, and the free education of the world's top schools. A MOOC campaign is sweeping China's [7]. Finally, Cross scholars in the study pointed out that, in order to better use information technology to improve the quality of education, the comprehensive study in "education reform and development Internet plus" era is adopted to promote and support educational equity [8].

\section{Method}

\subsection{Overall framework design of the system}

The English online teaching system designed can be divided into three parts: the front, the back and the database.

The front design of the system is mainly used to display the common users provided to the system, that is, the functions that the learners can access and thus use, including the registered login system, the campus news browsing, the online course information, the learning communication area and the individual, etc. The effective users of the login system can search the course or study on the page. With problems encountered in the process, the user can click to see the specific information and questions with related answers. The back is mainly used to manage system users, user data and teaching resources. In the whole design of the system, the design of the database is undoubtedly a very important part, and only the administrator has the authority to operate the database in the back.

The system front is connected with most of the functional modules, and the data involved is numerous, such as course information, all kinds of information, user login information and so on. In the design of the system front, the key is the division of the structure and the design of the frame. In general, it is not only the wide applicability of the system but also the simplicity of the style of the interface, which can also improve the enthusiasm of the learners to a certain extent. In addition, the design of the system structure should also take full account of the needs of program design, as much as possible with the division of the functional modules of the system.

The back of the system is mainly designed around the website information management and the effective maintenance of the back data. News and course information on the front page of the website are released and updated through the back. The function design of the system back is related to the operation and convenience of the system operation. Structurally speaking, the management of every functional module can be regarded as a branch of the background management module.

After completing the design of the front and back parts of the system, the design of the database part is also displayed in the structure of the system as a whole. The system front displays all kinds of information provided to learners and all kinds of data for background operation of the system, which are all stored in the database. 


\subsection{The model design analysis of the system function}

According to the analysis of the requirements of the system, the English network teaching system can roughly divide the system into the modules of login control, resource management, online teaching, interactive learning and system management.

Login control module: the user registered by this system can log in to the system and access the system response function according to the rights of the user. If the user forgets the password, the login password can be modified by the password management mechanism, and the password information of the background database can be automatically updated.

Resource management module: the management of this module can be divided into the online teaching module of the course management and teaching resources. The system administrator or teacher user will publish and update the course bulletin in the news center and other campus news, online learning link and so on, which can be used for students to visit, refer or study.

Interactive learning module: the design of interactive learning module in this system mainly includes study discussion and question answering. Interactive learning is one of the most typical features of MOOC teaching mode. Through this module, the learning network of the learners, which is connected with relevant contents, is realized; and the communication degree between teachers and students is also improved.

System management module: this system is based on MOOC pattern design. Openness, resource sharing and multi user concurrent access are all characteristics of this system. Data security and role differentiation are all inevitable features. Therefore, the user information management, role management and security management are set up in the system management module. And other functions, the specific functional modules are divided as shown in Figure 1.

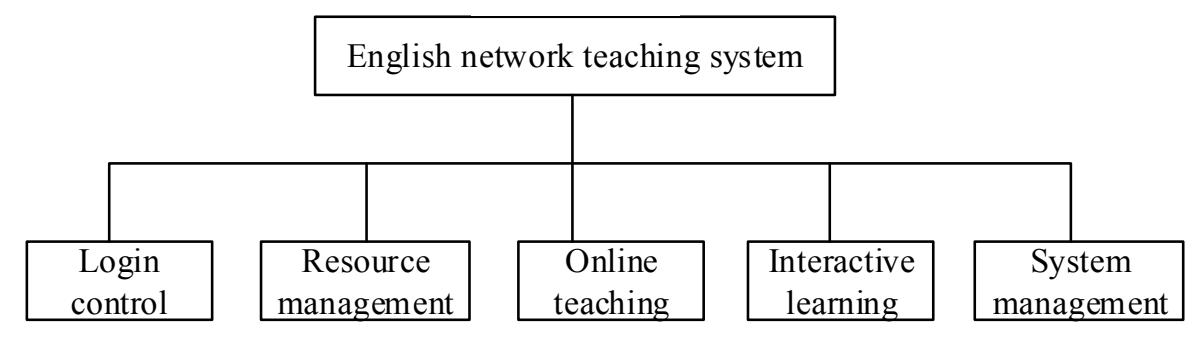

Fig. 1. The header image of online-journals.org

\subsection{Role function design of the system}

When the function module is designed for the English network teaching system, the subsystem can be divided according to the business process analysis of the system, and then each function module can be divided according to the characteristics of the subsystem. Through the structural analysis and design of the system, the system is 
modularized, and its overall goal is to get relatively high-quality products with a lower cost.

Through the analysis, this system can be divided into the basic structure of the front and the back. The front mainly aims at the student users, and the backstage is mainly for the administrator to manage and maintain the system. Specifically, according to the analysis of non-frequent visitors, the system can be divided into the functional block diagram as shown in Figure 2.

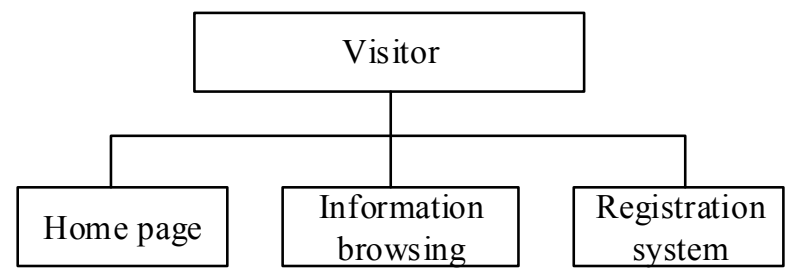

Fig. 2. Non-user function block graph

Specifically, according to the analysis of student members, the system can be divided into functional block diagrams as shown in Figure 3. Among which,

First, front page of the website: the student users registered in this system; after the login interface to enter their legitimate username and password; after the successful login, they are presented with the home page.

News Center: any legal student user who can access the system can access and check the news in the news module of this system.

Curriculum Center: after user login, the online learning module can be directly clicked online; and online learning or video courses will be evaluated.

Resource Center: after student login to the system, they can input keywords to retrieve their courseware and other teaching resources; or download them.

Personal Center: the student user has its own personal center module. In this module, students can view their personal information, training plans, study progress, and manage their own topics and comments, and also have hyperlinks for students to click into the chat room.

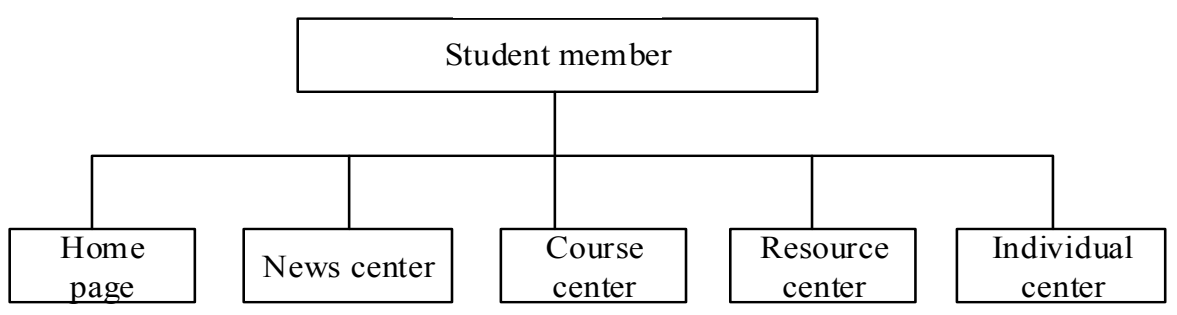

Fig. 3. Student user function block graph

According to the analysis of the teacher user, the system can be divided into the functional block diagram as shown in Figure 4. Among which, 
The front page of the website: to users who have the authority of the teacher, after entering the login interface with their legitimate username and password, the first presentation to the user is the homepage of the website.

News Center: any effective teacher user who can access the system can access and view the news in the system's news module, can also publish information on the course bulletin.

Curriculum Center: teachers can check courses and post courses after logging into the system and answer questions for students online.

Resource Center: teachers can use and post learning resources after logging into the system.

Personal Center: teacher users have their own personal center module. In this module, teachers can view their personal information, the published courses and resources, the topics and comments published by themselves, and also have hyperlinks for teachers to click into the chat room.

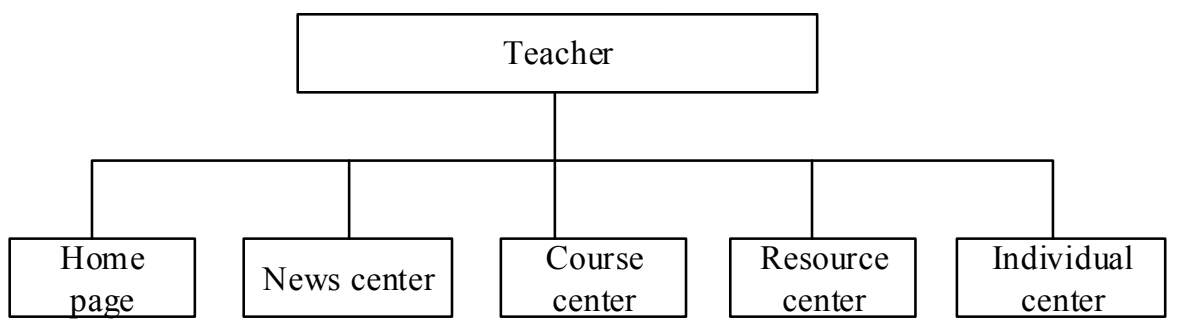

Fig. 4. Teacher user function block graph

According to the administrator analysis, the system is divided into the functional module diagram as shown in Figure 5:

Home page: after the administrator enters the login interface with the correct username and password, the first presentation to the administrator is the home page, and then a special interface that can be entered into the system administrator by clicking on the backstage management.

User management: a system administrator can manage ordinary users, increase user information, delete, check or modify operations.

News management: the campus news to be published requires administrators to operate, update and manage campus news according to the progress of teaching.

Curriculum management: the video course that needs to be uploaded to this system for students to be used by the student must be reviewed by the administrator in terms of format, size, validity and legitimacy of the video files to be uploaded. After the audit is passed, the administrator can upload and publish it by the administrator. The administrator also needs to display the video on the front page according to the progress of the teaching. The frequency list is updated.

Resource Management: teaching resources, such as courseware that needs to be uploaded to this system for students to be used for learning, must be reviewed by administrators to upload file format, size, validity, legitimacy and so on. After approval, it 
can be uploaded and released by the administrator and updated according to the teaching situation.

Teaching Supervision: the system administrator unregularly supervises and views the learning situation of the students. They also will hold those users with bad behavior to accountable, behaviors like comments with nothing to do with learning in the system, or worse, affecting the learning atmosphere of the whole system.

System Maintenance: system administrators need to maintain systems periodically, identify problems, analyze problems and solve problems in time, so that the system can run efficiently.

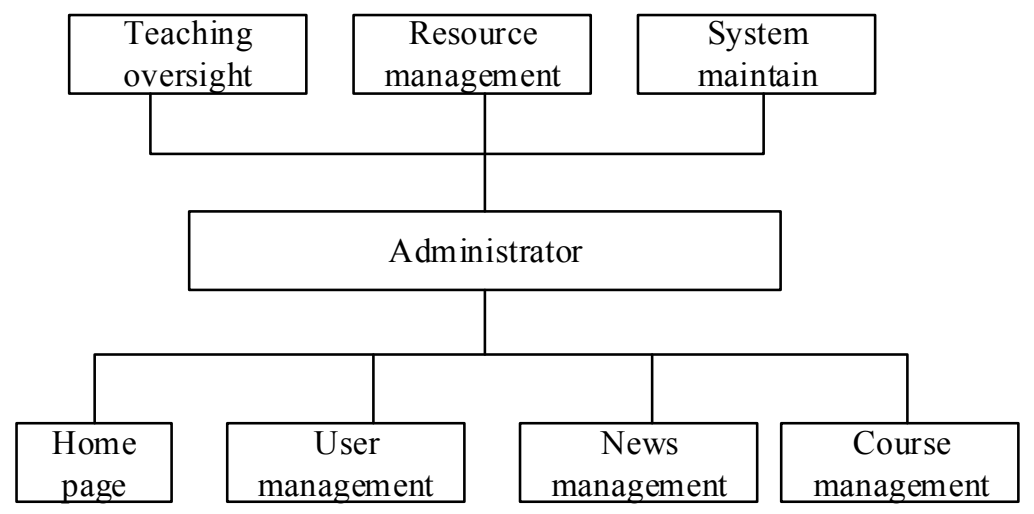

Fig. 5. Administrator user function block graph

\subsection{The design of the system function framework}

Front end server framework design:

First, copy the entire Fckeditor folder after the unzip to the WebContent path of Project; import the Fckeditorjs file in the page that will be used, because Fckeditor uses jQuery here, so the corresponding jquery.js is also imported; the JS code is properly modified to copy to the page to use Fckeditor as required. Modify the web.xml file.

Back end server framework design:

The system uses the integrated framework of Struts+Spring+Hibernate, which uses Struts as the overall infrastructure of the system, is responsible for the separation of MVC, the model part of the Struts framework, the service jump, the support of the persistent layer by the Hibernate framework, the management of Spring, and the management of struts and Hibernate. First, create a Dynamic Web Project in Eclipse, which is named classnet, unzip the war package struts2-blank under the apps folder in Struts, and then copy the jar package within the WEB-INF/lib and the files under the WEB-INF. Record the corresponding package. Create JSP files under WebContent, configure contents of struts.xml and web.xml.

Next, copy the jar package under the lib/required under Hibernate and the jar package under lib/jpa to the Lib directory of classnet project. Add packages, create inter- 
faces and classes, create tables in the database, create Hibernate mapping files for data tables, build Hibernate configuration files, and modify business logic implementation classes.

Then, include all the jar'packages in the LIBS directory of Spring to the Lib directory of the project. Write the configuration file applicationContext.xml of Spring under SRC directory. And configuring context-param to specify the path in web.xrnl, after introducing Spring, we need to use Spring for unified transaction management. Both data sources and sessionFactory are given to Spring to generate and modify the business logic implementation class. Delete Hibernate's configuration file Hibernate.cfg.xml and factory class HibernateSesseionFactory class. Their work has been handed over to Spring and is no longer useful.

Finally, modify the web.xml and load the Spring. Modify the configuration file struts.xml for Struts.

\section{$4 \quad$ Results and discussions}

\subsection{The realization of the system MOOC model}

Openness realization: one of the features of MOOC is its openness. It means that the learners can come from anywhere; the information source, the evaluation process, the learning environment are all open. The design of the system fully embodies this feature of the MOOC, and the students do not need to provide too much personal information, they can use it after the real name is registered through the mailbox. No matter when and where to login, user can experience online learning.

Interactive learning: interactive learning is an important feature of the MOOC model. This system uses online learning, online curriculum review, topic communication and online real-time chat rooms to achieve interactive learning, providing better communication and communication between learners and students and teachers.

Concurrency implementation: MOOC supports multiple users to access the system and online learning, but when a large number of user access at the same time, it is bound to affect the speed of access, and then affect the students' learning enthusiasm. Based on this problem, the system uses the front-end optimization strategy when the system is designed. Front end optimization mainly includes dynamic content static and front-end cache. Page static refers to the JSP dynamic web page that contains a large number of dynamic elements and converted to a HTML static page. As static pages do not load dynamic elements, their access speed is much faster than that of dynamic pages, which can increase access speed and reduce database pressure; front page caching is on the front end of the system on the Web server page. The surface is cached. The Hibernate persistence middleware is used to manage data, separate application layer from database layer, and add a part in the middle to avoid accessing database directly. Middleware is also responsible for transaction processing and data connection management. Multiple client connections can share a database connection through middleware. 
Portability implementation: because this system is a MOOC learning platform for large-scale students and there are more browsers and operating systems available on the mobile and PC side, therefore, the compatibility of the system and the use of cross platform are the aspects that must be considered, and the FCK editor of this system is powerful and easy to configure. Cross browser, which supports a variety of programming languages, have open source and other characteristics, can effectively solve this problem.

Security realization: this system can be accessed and used by large users, so security is also the focus of the design, and this system uses the best security system under Spring, that is, Acegi Security, which is a security framework that can provide descriptive security protection for Spring based application systems. It provides a set of Bean that can be configured in the context of Spring application, making full use of Spring's support for dependency injection and aspect-oriented programming. When protecting Web application system, Acegi uses Servlet filter to intercept Servlet requests, so as to implement identity authentication and enforce security. And Acegi has adopted a unique mechanism to declare the Servlet filter, which can use Spring IoC to inject other objects that it depends on. Acegi can also enforce security at a lower level by means of a protection method call, using the Spring AOP, Acegi proxy object, and applying the "cut face" to the object to ensure that the user can call the protected method only when it has the right authorization.

\subsection{System function test}

System openness test: this system is based on the MOOC pattern design, with the typical features of the open system. The system can be accessed by entering the domain name of the system in the browser address bar. The user can use the complete function of the system by the registered user, and it is not restricted by time and other factors. After testing, the system meets the openness demand of MOOC mode.

Interactive learning test: learning and communication between learners and teachers and among students is an important feature of the MOOC learning model. After testing, the system has two interactive ways to discuss the interactive mode of discussion area and chat room. The interactive functional modules meet the needs of users, students, teachers and managers. The system can effectively communicate and interact with each other through the corresponding functional modules of the system.

Resource sharing test: users who have completed registration in this system can view or use part of the system to share. It is proved by test that administrators or teachers can share resources that are uploaded to the system storage equipment in the background after resource auditing, and it provides the rich media and rich resource environment for students' learning. Users can use related resources whenever and wherever they want, depending on their authority.

News bulletin test: the system administrator or teacher user will update the curriculum bulletin and other campus news in the news center, which can be used for students to visit and reference and to assist in the realization of the teaching link. 


\subsection{System function test}

The testing object of performance testing covers all the performance of the system, including system stability, reliability, handling capacity, load and so on. Various performance testing tools are used to simulate the real application environment of the system. Through the simulation of many aspects, including the normal condition of the system use, the abnormal load of the system operation, record peak value and low peak value, through analysis, the performance condition of the system can be obtained. The usual test methods include pressure test and load test. Table 1 shows the performance test cases of the system.

Table 1. Performance test

\begin{tabular}{|c|c|c|c|c|c|c|}
\hline $\begin{array}{c}\text { Concurrent } \\
\text { user number }\end{array}$ & $\begin{array}{c}\text { Average } \\
\text { response } \\
\text { time (s) }\end{array}$ & $\begin{array}{c}\text { Maximum } \\
\text { response tie } \\
\text { (s) }\end{array}$ & $\begin{array}{c}\text { Requests } \\
\text { dealt per } \\
\text { second }\end{array}$ & $\begin{array}{c}\text { Success } \\
\text { rate }\end{array}$ & $\begin{array}{c}\text { Clicking } \\
\text { rate per } \\
\text { second }\end{array}$ & $\begin{array}{c}\text { Traffic } \\
\text { (byte/second) }\end{array}$ \\
\hline 50 & 0.773 & 1.117 & 5 & $100 \%$ & 50 & 2067 \\
\hline 100 & 1.322 & 1.879 & 11 & $100 \%$ & 97 & 4356 \\
\hline 150 & 1,996 & 2.345 & 14 & $100 \%$ & 145 & 8677 \\
\hline 200 & 2.567 & 3.023 & 21 & $100 \%$ & 198 & 10346 \\
\hline
\end{tabular}

In this paper, the system response time is studied by controlling the number of concurrent use and the change of the number of requests. The system is tested under the condition of 50 people online, 100 people online, 150 people online and 200 online each. The test results show that the system runs steadily and the system load is smaller during the operation process. The faster the response speed of the system is, the shorter the response time is, and the average response time of the system is less than 2 seconds when the number of concurrent users is below 200. In general, this kind of operation consumes fewer system resources and fully satisfies the demand that the response time of the 200 users' simple operating system is less than 3 seconds. At the same time, the system is placed under an unfavorable environment for the system limit test. The test object mainly includes the login page, the form and so on. The system has good performance and can meet the expected design requirements.

\subsection{Response time test}

System response time test: response time refers to the total time when users send requests and receive services after system responding. The response time of a system is the total time to send the first byte from the user to the last byte.

System capacity test: handling capacity is measured by the response time and handling capacity of the system. The system traffic volume per unit time is mainly counted, and then the handling capacity of the system is calculated according to the traffic volume. Figure 6 is the handling capacity test result of the system implemented in this paper. 


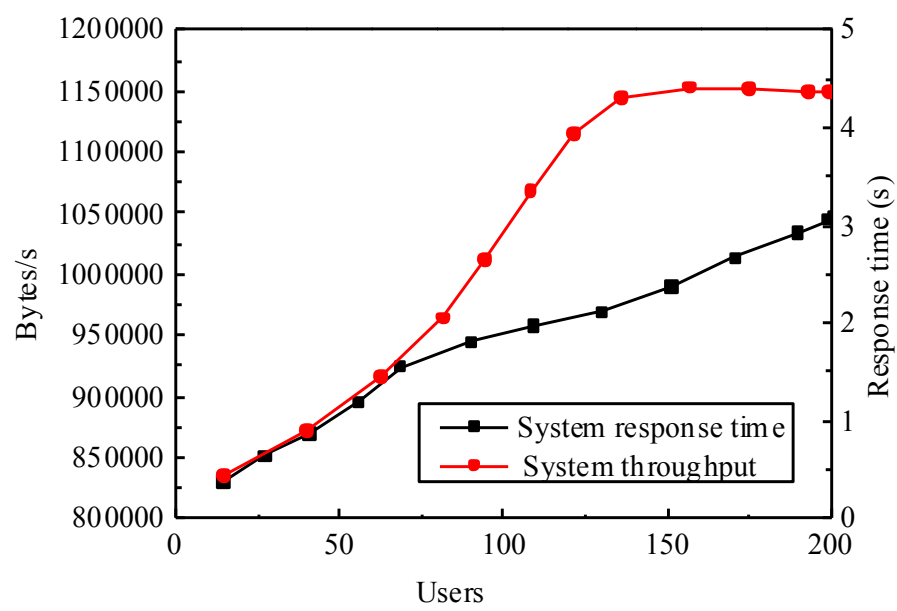

Fig. 6. System handling rate test

According to figure 7, the system can realize the operation of seven actions per minute. The response time of the system will increase with the increase of the number of system users. The system handling capacity is proportional to the number of system users, but the handling capacity of the system will gradually decrease when the number of users continues to increase.

\section{Conclusion}

Online education has become one of the growing trends in the development of education nowadays. The learning platform based on MOOC mode is deeply concerned by the majority of students and people. The research of English online teaching system based on MOOC mode is particularly important for developing and reforming higher education. Through the design and development of the system, the following works have been completed as a whole: first, more of the advantages and characteristics of MOOC mode are being figured out. Secondly, the J2EE solution based on SSH integration framework are further learned and applied. Thirdly, on the basis of the design and implementation of the system and the consolidation of relevant computer knowledge, the system has basically achieved the desired target, namely, the function of login management, resource management, curriculum management, online learning, interactive management and other modules. Finally, the system embodies the openness of MOOC learning mode, support for multi-user concurrent access, resource sharing, interactive learning and other typical characteristics.

The design and implementation of the course teaching system based on MOOC mode involve many theories, methods and techniques. There are many new problems to be solved in this system. It needs to be accumulated and perfected in practical application. In the following aspects, further research and development need to be done. In summary, the system has basically realized the functional modules, and the final 
realization effect of each module also effectively embodies the basic features of the MOOC mode, but the system is open to the users and supports the use of large-scale and multi user access. There are still some problems in the system testing, but they are all expected to be solved. In addition, with the increasing use and frequency of the system, the stability, anti-interference and large data storage of the system, the analysis of students' learning behavior can be further explored.

\section{Reference}

[1] Baran, T. A., Baraniuk, R. G., Oppenheim, A. V., Prandoni, P., \& Vetterli, M. (2016). Mooc adventures in signal processing: bringing dsp to the era of massive open online courses. IEEE Signal Processing Magazine, 33(4): 62-83. https://doi.org/10.1109/M SP.2016.2556004

[2] Möller, S., Ahrens, J., Altinsoy, M. E., Buchschmid, M., Fels, J., \& Hillmann, S., et al. (2017). A cross-university massive open online course on communication acoustics. Journal of the Acoustical Society of America, 141(5): 3556-3556. https://doi.org/10.1121/1.4 $\underline{987538}$

[3] Zhenhua, J. I. (2016). Application and empirical investigation of new mooc teaching system in computer application course. International Journal of Emerging Technologies in Learning, 11(5): 62. https://doi.org/10.3991/ijet.v11i05.5696

[4] Ying, Y. (2017). Application of flipped classroom teaching mode based on mooc in modern educational technology teaching. Journal of Computational \& Theoretical Nanoscience, 14(2): 1075-1078. https://doi.org/10.1166/jctn.2017.6405

[5] Rayyan, S., Fredericks, C., Colvin, K. F., Liu, A., Teodorescu, R., \& Barrantes, A., et al. (2016). A mooc based on blended pedagogy. Journal of Computer Assisted Learning, 32(3): 190-201. https://doi.org/10.1111/jcal.12126

[6] Trivedi, Y. (2016). Innovation \& competition: succeeding through global standards: a new massive open online course delivered on ieee x.org. IEEE Communications Magazine, 54(3): 7-9. https://doi.org/10.1109/MCOM.2016.7432164

[7] Kaplan, A. M., \& Haenlein, M. (2016). Higher education and the digital revolution: about moocs, spocs, social media, and the cookie monster. Business Horizons, 59(4): 441-450. https://doi.org/10.1016/j.bushor.2016.03.008

[8] Cross, S., \& Whitelock, D. (2017). Similarity and difference in fee-paying and no-fee learner expectations, interaction and reaction to learning in a massive open online course. Interactive Learning Environments, 25(2):180-185. https://doi.org/10.1080/10494820 .2016 .1138312

\section{Author}

Nina Zhang is with Shandong Management University, Shandong Jinan 250357, China.

Article submitted 23 February 2018. Final acceptance 05 May 2018. Final version published as submitted by the author. 